\title{
Comparison of the efficiency of endobronchial ultrasound-guided transbronchial needle aspiration using a 22G needle versus 25G needle for the diagnosis of lymph node metastasis in patients with lung cancer: a prospective randomized, crossover study
}

\author{
Tetsuya Sakai $^{1}{ }^{\wedge}$, Hibiki Udagawa $^{1} \wedge$, Keisuke Kirita ${ }^{1}$, Shogo Nomura $^{2}$, Ryo Itotani ${ }^{1}$, Yutaro Tamiya ${ }^{1}$, \\ Akira Sugimoto $^{1}$, Takahiro Ota ${ }^{1}$, Tomoyuki Naito ${ }^{1}$, Hiroki Izumi ${ }^{1}$, Kaname Nosaki ${ }^{1}$, Takaya Ikeda ${ }^{1}$, \\ Yoshitaka Zenke ${ }^{1}$, Shingo Matsumoto ${ }^{1}$, Kiyotaka Yoh $^{1}$, Seiji Niho ${ }^{1}$, Tokiko Nakai ${ }^{3}$, Genichiro Ishii ${ }^{3}$, \\ Koichi Goto ${ }^{1}$
}

${ }^{1}$ Department of Thoracic Oncology, National Cancer Center Hospital East, Kashiwa, Japan; ${ }^{2}$ Biostatistics Division, Center for Research Administration and Support, National Cancer Center, Kashiwa, Japan; ${ }^{3}$ Department of Pathology and Clinical Laboratories, National Cancer Center Hospital East, Kashiwa, Japan

Contributions: (I) Conception and design: T Sakai, H Udagawa, K Kirita, S Nomura, T Ota, K Goto; (II) Administrative support: T Sakai, H Udagawa, K Kirita, S Nomura, T Ota, S Matsumoto, K Yoh, S Niho, K Goto; (III) Provision of study materials or patients: T Sakai, H Udagawa, K Kirita, S Nomura, T Ota, R Itotani, Y Tamiya, A Sugimoto, T Naito, H Izuimi, K Nosaki, T Ikeda, Y Zenke, S Matsumoto, K Yoh, S Niho, K Goto; (IV) Collection and assembly of data: T Sakai, H Udagawa, K Kirita, S Nomura, T Ota, R Itotani, Y Tamiya, A Sugimoto, T Naito, H Izuimi, K Nosaki, T Ikeda, Y Zenke, T Nakai, G Ishii; (V) Data analysis and interpretation: All authors; (VI) Manuscript writing: All authors; (VII) Final approval of manuscript: All authors.

Correspondence to: Hibiki Udagawa, MD, PhD. Department of Thoracic Oncology, National Cancer Center Hospital East, 6-5-1 Kashiwanoha, Kashiwa, Chiba, 277-0882, Japan. Email: hudagawa@east.ncc.go.jp.

Background: Endobronchial ultrasound-guided transbronchial needle aspiration (EBUS-TBNA) is generally performed for the diagnosis of hilar/mediastinal lymph node metastasis in patients with lung cancer. Recently, a 25 -gauge $(G)$ needle became available, but robust evidence of its usefulness in routine clinical practice is still lacking.

Methods: A prospective randomized crossover trial was performed, in which patients with suspected hilar/ mediastinal lymph node metastasis of lung cancer underwent EBUS-TBNA. The primary endpoint was the rate of yield histology specimens containing malignant cells.

Results: From December 2018 to February 2020, 102 patients were randomly assigned to EBUS-TBNA using a $22 \mathrm{G}$ needle first, followed by a $25 \mathrm{G}$ needle $(\mathrm{n}=50)$ or EBUS-TBNA using a $25 \mathrm{G}$ needle first, followed by a $22 \mathrm{G}$ needle $(\mathrm{n}=52$ ). There was no difference in the diagnostic yield of malignancy between the histology specimens obtained by using the $22 \mathrm{G}$ and $25 \mathrm{G}$ needles ( $75 \%$ vs. $75 \%$, respectively, $\mathrm{P}=0.37$ ). The sizes of the tissue samples (16.4vs. $4.9 \mathrm{~mm}^{2}$, respectively) and number of malignant cells in the tissue samples (626 vs. 400, respectively) were both significantly higher when using the $22 \mathrm{G}$ needle than when using the $25 \mathrm{G}$ needle.

Conclusions: No significant difference in the diagnostic yield between the $22 \mathrm{G}$ and $25 \mathrm{G}$ needles was observed for the diagnosis of lymph node metastasis of lung cancer, suggesting that needles of either gauge could be used for the biopsy. However, we would recommend use of the $22 \mathrm{G}$ needle, because it provided larger specimens and specimens containing larger numbers of malignant cells.

Trial Registration: University hospital Medical Information Network Clinical Trial Registry (ID: UMIN000036680).

\footnotetext{
^ ORCID: Tetsuya Sakai, 0000-0001-5884-2735; Hibiki Udagawa, 0000-0001-8822-2684.
} 


\begin{abstract}
Keywords: Lung cancer; bronchoscopy; endobronchial ultrasound-guided transbronchial needle aspiration (EBUS-TBNA); randomized trial
\end{abstract}

Submitted Jun 09, 2021. Accepted for publication Aug 24, 2021.

doi: $10.21037 /$ tlcr-21-480

View this article at: https://dx.doi.org/10.21037/tlcr-21-480

\section{Introduction}

Endobronchial ultrasound-guided transbronchial needle aspiration (EBUS-TBNA) is a well-established and minimally invasive tool for sampling of mediastinal and hilar lymph nodes $(1,2)$.

In addition to histopathological diagnosis, tissue sampling has also come to be recognized recently as being crucial for biomarker analysis of tumors (3), such as for the detection of epidermal growth factor receptor gene mutations, anaplastic lymphoma kinase gene fusions, and programmed death ligand 1 expression in lung cancer, which would allow individualized selection of the best therapeutic approach for patients with advanced non-small cell lung cancer $(4,5)$. Therefore, high diagnostic rate and appropriate yield of tissue samples for biomarker analysis of EBUS-TBNA are desired.

The quality of the specimen obtained and the diagnostic yield of EBUS-TBNA are influenced by the needle used for the biopsy, and several needles are available, including needles of various sizes. The American College of Chest Physicians guideline for EBUS-TBNA recommends the use of either a 21-gauge (G) needle or 22G needle (6). Recently, a 25G EBUS-TBNA needle has become available, but there are only studies that evaluate the efficiency of $25 \mathrm{G}$ needle retrospectively $(7,8)$, no robust data yet to support its use in routine clinical practice.

In the case of endoscopic ultrasound-guided fine needle aspiration (EUS-FNA) biopsy for pancreatic cancer, several studies have demonstrated higher diagnostic accuracy rates with $25 \mathrm{G}$ needles than with $22 \mathrm{G}$ needles. The observed superior diagnostic accuracy for pancreatic cancer of EUSFNA using the $25 \mathrm{G}$ needle is considered to be attributable to its being associated with a lower risk of bloody aspiration than a $22 \mathrm{G}$ needle, and the needle passage into some lesions being possibly technically easier with a $25 \mathrm{G}$ needle than with a $22 \mathrm{G}$ needle. Even though EBUS-TBNA and EUSFNA are different procedures and the target lesions are different, the techniques are similar. Therefore, there is the possibility that the use of a $25 \mathrm{G}$ needle may also be associated with a higher diagnostic accuracy in EBUSTBNA, as in EUS-FNA.

Few studies have yet addressed the differences in performance between $22 \mathrm{G}$ and $25 \mathrm{G}$ needles in EBUSTBNA. We performed a prospective randomized crossover clinical trial to compare the diagnostic accuracy and sample quantity and quality of EBUS-TBNA performed using a $22 \mathrm{G}$ needle and a $25 \mathrm{G}$ needle, in order to determine which of the two could be recommended based on a higher diagnostic rate and higher yield of larger tissue samples that may be appropriate for biomarker analysis.

We present the following article in accordance with the CONSORT reporting checklist (available at https://dx.doi. org/10.21037/tlcr-21-480).

\section{Methods}

\section{Study design}

This was a single-center, prospective randomized, crossover study conducted at the National Cancer Center Hospital East at Kashiwa, Japan, between December 2018 and February 2020.

\section{Ethical considerations}

The study protocol and associated documents were approved by the Institutional Review Board of the study center (National Cancer Center Japan: approval number 2018-016). The study was conducted in compliance with the principles of the Declaration of Helsinki and local regulations. Informed consent was obtained from all patients at enrollment.

\section{Patients}

Patients who were 20 years of age or older were eligible for enrollment if they had suspected or diagnosed primary lung cancer based on the findings of chest computed tomography (CT) and were scheduled to undergo EBUS-TBNA for 


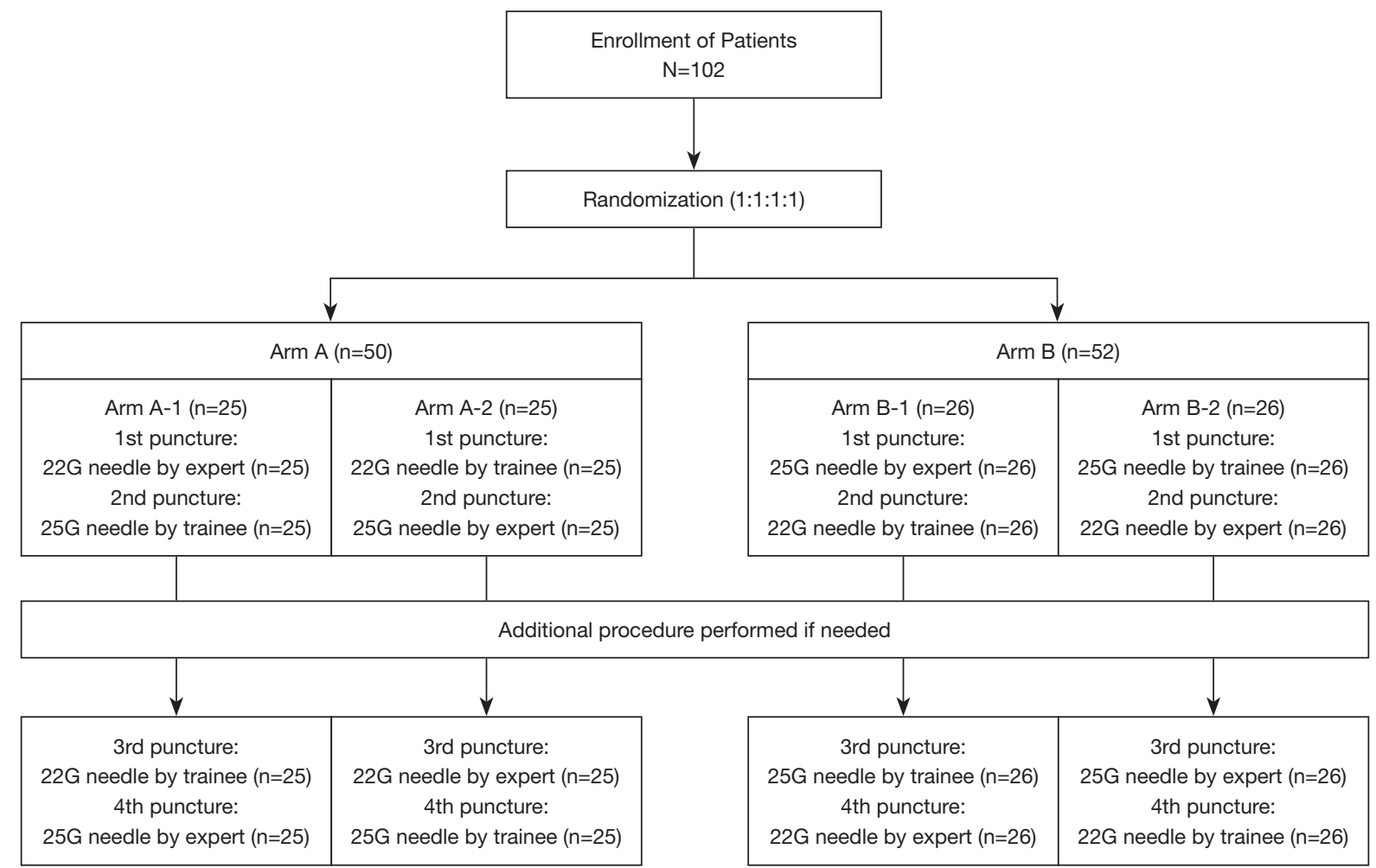

Figure 1 Study flowchart.

suspected hilar/mediastinal lymph node metastasis based on the presence of hilar/mediastinal lymphadenopathy, defined as enlargement ( $\geq 10 \mathrm{~mm}$ in short-axis diameter) on chest CT or increased [18F]-fluorodeoxyglucose uptake (standardized uptake value max $>2.5$ ) on positron emission tomography-CT. Patients who needed multi lymph node punctures for lymph node staging were ineligible. Patients were ineligible if they had hypersensitivity to lidocaine, midazolam, flumazenil, and pethidine hydrochloride or serious hypersensitivity to other drugs, or had current treatment with antiplatelet agents or anticoagulants, serious complications or comorbidities (heart disease, interstitial pneumonia, poorly controlled hypertension, among others).

\section{Randomization and masking}

At the time of bronchoscopy, each patient was randomly assigned to one of four groups: (I) $22 \mathrm{G}$ needle-first, followed by the $25 \mathrm{G}$ needle, by an expert operator; (II) $22 \mathrm{G}$ needle-first, followed by the $25 \mathrm{G}$ needle, by a trainee operator; (III) $25 \mathrm{G}$ needle-first, followed by the $22 \mathrm{G}$ needle, by an expert operator; (IV) $25 \mathrm{G}$ needle-first, followed by the $22 \mathrm{G}$ needle, by a trainee operator, at a 1:1:1:1 ratio. Hereafter, the first two groups are referred to as Arm A and the last two groups as Arm B (Figure 1). The randomization was stratified by the lymph node size $(<10 v s . \geq 10 \mathrm{~mm})$ and location of the lymph node (\#4L vs. not \#4L). The open-source web response system (smartEDC) based on a permuted-block method was used for the randomization. Upon randomization, subjects were assigned a unique randomization number, which was kept in an independent Data Center (National Cancer Center Exploratory Oncology Research and Clinical Trial Center) at the National Cancer Center Hospital East. Although the randomized allocation of a patient was open to the operator performing the EBUS-TBNA, the personnel involved in the histopathological evaluations were blinded to the allocated group.

\section{EBUS-TBNA method}

For patients in Arm A, EBUS-TBNA was performed using a $22 \mathrm{G}$ needle first, and then with a $25 \mathrm{G}$ needle (Expect pulmonary; Boston scientific, Marlborough, MA, USA), 
and for those in Arm B, EBUS-TBNA was performed using a $25 \mathrm{G}$ needle first, and then with a $22 \mathrm{G}$ needle. All patients were scheduled to undergo EBUS-TBNA using both the $22 \mathrm{G}$ and $25 \mathrm{G}$ needles. In Arm A, a 3rd puncture was performed with the $22 \mathrm{G}$ needle and a 4th with the 25G needle. In Arm B, a 3rd puncture was performed with the $25 \mathrm{G}$ needle and a 4 th puncture with the $22 \mathrm{G}$ needle. Only one puncture was performed in each EBUS-TBNA procedure using the pre-determined needle. Patients of either arm in whom the pre-planned procedures had been completed were allowed to undergo any additional procedures if they were considered as being necessary by the operator.

The bronchoscopy procedure adopted was as previously described $(9,10)$. In this study, the bronchoscopy was performed by expert operators with the experience of performing EBUS-TBNA in over 200 cases (HU and $\mathrm{KK}$ ) and trainee operators with the experience of performing EBUS-TBNA in at least 30 cases (TS, RI, YT, AS, TO, TN). The same operator inserts and holds the bronchoscope, and also handles the needle passes. Another person assists the procedure. A convex probe was used for the EBUS (CP-EBUS; BF-UC260FW, Olympus Ltd., Tokyo, Japan).

Before the bronchoscopy procedure was begun, topical anesthesia of the larynx and pharynx was induced with a $2 \%$ lidocaine $(5 \mathrm{~mL})$ spray. Pethidine hydrochloride $(17.5$ $\mathrm{mg}$ or $35 \mathrm{mg}$ ) and midazolam $(2-3 \mathrm{mg})$ were administered as intravenous anesthesia. During the bronchoscopy, 2\% lidocaine $(1-2 \mathrm{~mL})$ was administered through the channel of the scope and midazolam $(1 \mathrm{mg})$ was administered intravenously, as necessary.

The procedure time for each puncture was recorded as the time from insertion of the needle to removal of the needle from the bronchoscope channel. The total duration of the bronchoscopy was calculated as the time from insertion of the bronchoscope through the vocal cords to the time of withdrawal of the bronchoscope.

\section{Histological assessment}

For this study, hematoxylin-and-eosin (HE) stained and/ or immunohistochemistry slide prepared from each specimen were reviewed, and the histological diagnosis was made according to the 4th edition of the World Health Organization Classification of Lung Tumors (11). Morphological diagnosis was determined on the basis of the findings in the H-E-stained slides. The tissue sample sizes obtained were calculated by multiplying the length of the major and minor axes of the HE stained samples. For tissue sample size measurement in virtual slides, the surfaces areas were measured using a high-resolution digital slide scanner (NanoZoomer S210, Hamamatsu Photonics kk, Hamamatsu, Japan). The percentage of malignant cells was counted in virtual slides, as the proportion of malignant cell nuclei among the nucleated cells in the tissue. The percentage of malignant cells were scored as $0 \%, 5 \%$, and in multiples of $10 \%$. Because a percentage of malignant cells of $30 \%$ or more is considered as being the appropriate percentage for the analysis by next-generation sequencing (NGS), we set the threshold at $30 \%$. The number of malignant cells contained in the specimen were counted in the virtual slides and measured up to 2,000 malignant cells and measured more than 2,000 cells by 100 cell unit. The area occupied by red blood cells (RBC) was evaluated in virtual slides and scored as $0 \%, 1-10 \%, 11-20 \%, 21-30 \%$, or more than $31 \%$.

\section{Safety}

Bleeding events were evaluated for each puncture; the bleeding events were categorized into three grades (mild, moderate, or severe) defined according to the clinical interventions required, which was previously reported definition (12). Mild bleeding was defined as bleeding that did not require any treatment, and moderate bleeding was defined as bleeding that could be controlled by suctioning. Severe bleeding was regarded as bleeding that necessitated additional interventions, such as instillation of ice-cold saline or a diluted vasoconstrictive drug, balloon tamponade, argon plasma coagulation, conversion to rigid bronchoscopy, or mechanical ventilation. Other adverse events (AEs) were graded using the Common Terminology Criteria for Adverse Events version 4.0 (CTCAE v4.0). The observation period of AEs was from the end of the bronchoscopy procedure to one hour after completion of the procedure. Serious adverse events (SAEs) causally related to the bronchoscopy were recorded at any time that they occurred, even after the end of the observation period.

\section{Endpoints}

Patients were scheduled to undergo EBUS-TBNA punctures four times according to the study protocol, and our primary interest was in the diagnostic properties of the first two punctures. EBUS-TBNA after the fourth puncture 
was also allowed as an out-of-protocol procedure(s). "EBUS-TBNA puncture" is a distinct entry and exit of needle through the air way wall, and each EBUS-TBNA puncture includes 20 to 30 agitations of the needle within the target lymph node. All EBUS-TBNA procedures were done without withdrawal of the bronchoscopy. All the endpoints, except for the AEs after the bronchoscopy, were calculated for each of the EBUS-TBNAs, i.e., the variables were calculated four times for each patient.

The primary endpoint was the rate of yield histology specimens containing malignant cells by the first two punctures. A secondary endpoint was the rate of yield histology specimens containing malignant cells by the 1 st to the 4th puncture. The other secondary endpoints included the rate of yield of adequate specimens for the histopathological diagnosis, the morphological diagnosis rate, the time taken for the puncture(s), and the incidence rate of moderate to severe bleeding and AEs. The exploratory endpoints included the rate of yield of histology specimens containing malignant cells according to the experience of the operator, the sizes of the tissue samples obtained, the percentage of malignant cells, the number of malignant cells in the tissue samples, and the percent area occupied by RBC.

The rate of yield of histology specimens containing malignant cells was defined as the percentage of patients whose histology specimens contained malignant cells. The rate of yield of adequate specimens for histopathological diagnosis was defined as the percentage of patients whose histology specimens showed any evidence for the histopathological diagnosis, such as malignant cells, lymphoid tissue and necrotic tissue. Non-adequate histology specimens were defined as the absence of specimen or specimens only containing cartilage or clots.

\section{Statistical analysis}

This study was designed to determine which needle was more advantageous in terms of the rate of yield of histology specimens containing malignant cells. Based on the consideration that the outcome of the second EBUS-TBNA may not be affected by that of the first, a crossover design was adopted. In an observational database of 42 patients in our hospital, the rates of yield of malignant cells in histology specimens obtained with the $22 \mathrm{G}$ and $25 \mathrm{G}$ needles were both $70 \%$. Based on this data, we hypothesized that the expected yield rate of histology specimens containing malignant cells with a superior needle would be $80 \%$ and that with an inferior needle would be $60 \%$. Given the assumption that the patients who show malignant cells in the histology specimens regardless of the selected needle accounted for $48 \%$, 100 patients (44 patients with discordant outcomes between the two needles) were required to be enrolled to obtain a two-sided significance level of $5 \%$ and statistical power of $80 \%$. In the blinded study monitoring in December, 2019, we found that the number of such patients with discordant pairs was approximately 20, which would result in a serious loss in power. Considering a feasibility issue for additional enrollment, study investigators reached a consensus to perform the primary analysis for patients who had been enrolled at that time. No interim analyses were planned in this study.

All the endpoints were analyzed for all the randomly assigned patients on an intention-to-treat basis. The rates of yield were compared using the Mainland-Gart test. For sensitivity analysis, exact and standard $\mathrm{McNemar}$ tests were used. Because we planned to enroll patients who could undergo EBUS-TBNA procedures at least four times, analysis of cases with missing data was not planned. For estimating the efficacy of use of a $25 \mathrm{G}$ needle versus a $22 \mathrm{G}$ needle, a conditional logistic regression analysis and generalized mixed effects model were applied. The timing of the EBUS-TBNA procedures and the experience of the operators were included as factors for adjustment in the two models. The same analysis methods were used for the secondary endpoints, except for SAEs and AEs. Statistical comparisons of the tissue sample sizes measured in virtual slides and the puncture times between the $22 \mathrm{G}$ needle and $25 \mathrm{G}$ needle were conducted using the Wilcoxon signedrank test, Pearson $\chi^{2}$ test, or Fisher's exact test. Statistical analyses were performed using $\mathrm{JMP}^{\circledR}$ version 11.1.1 (SAS Institute Inc., Cary, NC, USA) and SAS Release 9.4 (SAS Institute Inc.).

\section{Results}

\section{Patients and procedure}

Between December 2018 and February 2020, a total of the 102 patients were enrolled. All the enrolled patients were randomly assigned to Arm A (1st puncture with a $22 \mathrm{G}$ needle, followed by the 2 nd puncture with a $25 \mathrm{G}$ needle; $\mathrm{n}=50$ ) or Arm B (1st puncture performed with a $25 \mathrm{G}$ needle, followed by the 2 nd puncture performed with a $22 \mathrm{G}$ needle; $\mathrm{n}=52)$. All patients underwent EBUS-TBNA four times (Figure 1). The data cutoff date was April 6, 2020. 
Table 1 Characteristics of the patients and the punctured lesion

\begin{tabular}{|c|c|c|c|}
\hline Characteristics & Total & $\operatorname{Arm~A}$ & Arm B \\
\hline Sex, male & $71[70]$ & 34 [68] & 37 [71] \\
\hline Age, years, median [range] & 70 [42-83] & $71[44-83]$ & 68 [42-83] \\
\hline Positive smoking history & $87[86]$ & $43[86]$ & $44[85]$ \\
\hline Prior chemotherapy & 7 [7] & $5[10]$ & $2[4]$ \\
\hline \multicolumn{4}{|c|}{ Location of the punctured lesion } \\
\hline \#4L & $6[6]$ & $2[4]$ & $4[8]$ \\
\hline Non \#4L & $96[94]$ & $48[96]$ & 48 [92] \\
\hline \#4R & 41 & 19 & 22 \\
\hline \#7 & 41 & 22 & 19 \\
\hline$\# 11$ & 8 & 4 & 4 \\
\hline \multicolumn{4}{|l|}{ Lesion diameter, mm } \\
\hline Median [range] & $18[8-75]$ & $20[9-75]$ & $17[8-40]$ \\
\hline$<10 / \geq 10 \mathrm{~mm}$ & $4[4] / 98[96]$ & $2[4] / 48[96]$ & $2[4] / 50[96]$ \\
\hline
\end{tabular}

ECOG, Eastern Cooperative Oncology Group; PS, performance status.

The patient characteristics are shown in Table 1. About $70 \%$ of the patients in both Arm A and Arm B were male. The median age of the patients in Arm A was 71 years and that of the patients in Arm B was 68 years. Only six of all the patients $(6 \%)$ underwent EBUS-TBNA for a station \#4L lymph node: 2 patients were allocated to Arm A, and 4 to Arm B. The median lesion diameter was 20 (range, 9-75) $\mathrm{mm}$ in Arm A and 17 (range, 8-40) $\mathrm{mm}$ in Arm B. There was no statistically difference in the age, sex, smoking history, ECOG PS, distribution of the lesion location, or lesion size between Arm A and Arm B.

The median total duration of the bronchoscopy was 20.9 (10.6-41.0) minutes. The median duration of the puncture with the $22 \mathrm{G}$ needle was $2.0(0.9-6.2)$ minutes and that of the puncture with the $25 \mathrm{G}$ needle was 1.8 (1.0-3.6) minutes in the 1st and 2nd punctures (Wilcoxon's rank-sum test; $\mathrm{P}=0.21$ ).

\section{Rate of yield of histology specimens containing malignant cells}

The yield rate of histology specimens containing malignant cells obtained using the $22 \mathrm{G}$ needle was $75 \%$ (76/
102 patients) in the 1st puncture of arm $\mathrm{A}$ and 2 nd puncture of $\operatorname{arm~B}$, and that in the specimens obtained with the $25 \mathrm{G}$ needle was also $75 \%$ (77/102 patients) in the 2 nd puncture of arm $\mathrm{A}$ and 1st puncture of arm B (two-sided $\mathrm{P}$ value calculated by the Mainland-Gart test, $\mathrm{P}=0.37$; Figure 2); thus, the primary objective of the study was not met. Using a generalized mixed effect model, the estimated odds ratio of detecting malignant cells in the histological specimens with the $25 \mathrm{G}$ needle to $22 \mathrm{G}$ needle was 1.062 (95\% CI, 0.644-1.750), which corresponded to a non-significant difference in the yield rate of histology specimens containing malignant cells between the two needles. In regard to the results of the 1st to 4th punctures, the yield rates of histology specimens containing malignant cells obtained with the $22 \mathrm{G}$ needle and $25 \mathrm{G}$ needle were $85 \%$ and $87 \%$, respectively (Figure 3). There were 4 patients whose specimens containing malignant cells only obtained by $22 \mathrm{G}$ needle, and 6 patients only obtained by $22 \mathrm{G}$ needle. There was no statistically difference in the age, sex, smoking history, ECOG PS, distribution of the lesion location (\#4L or not \#4L), or lesion size between those 
Rate of yield of histology specimens with malignant cells ( $\mathrm{N}=102)$

22G needle

\begin{tabular}{ccccc} 
& Malignant cells & Positive & Negative & Total, n [\%] \\
\hline 25G needle & Positive & 65 & 12 & $77[75]$ \\
& Negative & 11 & 14 & $25[25]$ \\
& Total, $\mathrm{n}[\%]$ & $76[75]$ & $26[25]$ & $\mathrm{P}=0.37$ \\
\hline
\end{tabular}

Rate of yield of adequate specimens for histopathological diagnosis $(\mathrm{N}=102)$

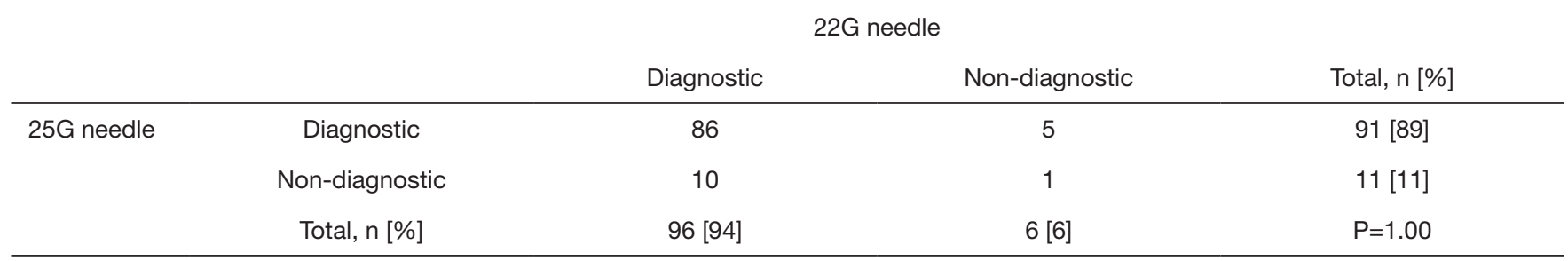

Figure 2 Rate of yield of histology specimens with malignant cells and rate of yield of adequate specimens for histopathological diagnosis in the 1 st and 2 nd punctures.

Rate of yield of histology specimens with malignant cells [ $\mathrm{N}=102]$

\begin{tabular}{|c|c|c|c|c|}
\hline & \multicolumn{4}{|c|}{$22 \mathrm{G}$ needle } \\
\hline & Malignant cells & Positive & Negative & Total, n [\%] \\
\hline \multirow{3}{*}{ 25G needle } & Positive & 83 & 6 & 89 [87] \\
\hline & Negative & 4 & 9 & 13 [13] \\
\hline & Total, n [\%] & 87 [85] & 15 [15] & \\
\hline
\end{tabular}

Rate of yield of adequate specimens for histopathological diagnosis[ $\mathrm{N}=102]$

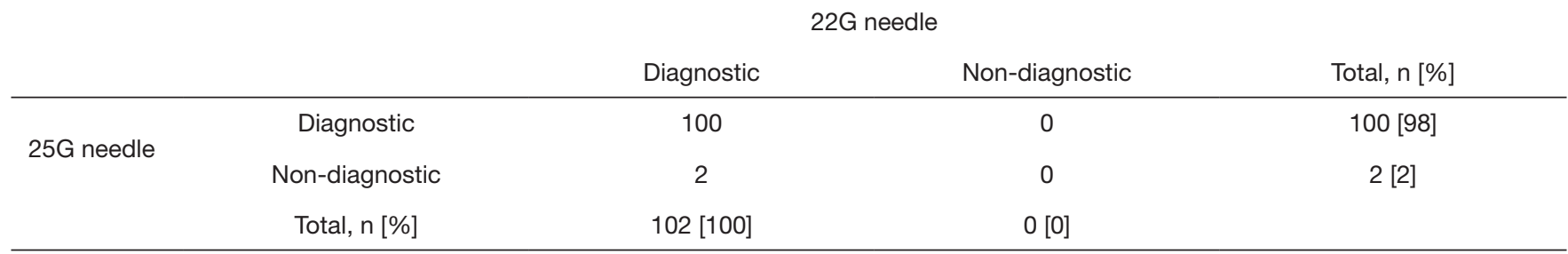

Figure 3 Rate of yield of histology specimens with malignant cells and rate of yield of adequate specimens for histopathological diagnosis in the 1 st to 4 th punctures.

patients. There was a small difference in the yield rate of histology specimens containing malignant cells according to the experiences of the operators when the $22 \mathrm{G}$ needle was used [82\% (84/102 patients) for expert operators and $75 \%$ (76/102 patients) for trainee operators; McNemar test; $\mathrm{P}=0.045]$, but not for the punctures using the $25 \mathrm{G}$ needle $[76 \%$ (78/102 patients) for expert operators and $75 \%$ (76/102 patients) for trainee operators; McNemar test;
$\mathrm{P}=0.68]$ (Figure 4).

\section{Rates of yield of adequate specimens for histopathological diagnosis}

In the 1 st and 2 nd punctures, the yield rates of adequate specimens for histopathological diagnosis obtained with the $22 \mathrm{G}$ and $25 \mathrm{G}$ needles were $94 \%$ and $89 \%$, respectively 
Obtained with the $22 \mathrm{G}$ needle [N=102]

\begin{tabular}{|c|c|c|c|c|}
\hline & \multicolumn{4}{|c|}{ Expert operators $^{a}$} \\
\hline & Malignant cells & Positive & Negative & Total, n [\%] \\
\hline \multirow{3}{*}{$\begin{array}{l}\text { Trainee } \\
\text { operators }^{\text {b }}\end{array}$} & Positive & 72 & 4 & 76 [75] \\
\hline & Negative & 12 & 14 & 26 [25] \\
\hline & Total, n [\%] & $84[82]$ & $18[18]$ & $P=0.045$ \\
\hline
\end{tabular}

Obtained with the $25 \mathrm{G}$ needle [N=102]

\begin{tabular}{lcccc} 
& \multicolumn{2}{c}{ Expert operators $^{\mathrm{a}}$} & & Total, $\mathrm{n}$ [\%] \\
\hline Trainee & Malignant cells & Positive & Negative & $76[75]$ \\
operators $^{\mathrm{b}}$ & Positive & 65 & 11 & $26[25]$ \\
& Negative & 13 & 13 & $\mathrm{P}=0.68$ \\
\hline
\end{tabular}

Figure 4 Rate of yield of histology specimens with malignant cells according to the physician experience in the first to fourth punctures. ", operator with experience of over 200 cases of EBUS-TBNA. ${ }^{\text {, }}$, operator with experience of at least 30 cases of EBUS-TBNA.

Table 2 Morphological diagnosis

\begin{tabular}{lcc}
\hline \multirow{N}{*}{$=65^{\mathrm{a}}$} & 22G needle & 25G needle \\
\cline { 2 - 3 } & $\mathrm{n}[\%]$ & $\mathrm{n}[\%]$ \\
\hline Definitive morphological diagnosis & $44[68]$ & $39[60]$ \\
Adenocarcinoma & 22 & 17 \\
Squamous cell carcinoma & 3 & 2 \\
SCLC & 17 & 18 \\
Other & 2 & 2 \\
Morphological diagnosis unavailable & $21[32]$ & $26[40]$ \\
NSCLC-NOS & 19 & 25 \\
Carcinoma & 2 & 1 \\
\hline
\end{tabular}

a , both the $22 \mathrm{G}$ needle as well as $25 \mathrm{G}$ needle yielded specimens containing malignant cells in the $1^{\text {st }}$ and $2^{\text {nd }}$ puncture. SCLC, small cell lung cancer; NSCLC-NOS, non-small cell lung cancer not otherwise specified.

(Mainland-Gart test; $\mathrm{P}=1.00$ ) (Figure 2). In the results taking into account all of 1 st to 4 th punctures, the yield rates of adequate specimens for histopathological diagnosis obtained using the $22 \mathrm{G}$ and $25 \mathrm{G}$ needles were $100 \%$ and 98\%, respectively (Figure 3).

The specimens obtained using the $22 \mathrm{G}$ needle tended to show a higher morphological diagnosis rate as compared to the specimens obtained using the $25 \mathrm{G}$ needle $(\mathrm{McNemar}$ test; $\mathrm{P}=0.16$ ) (Table 2).

In 9 of the 102 patients, no malignant cells were detected in any of the histology samples obtained by the
1 st to the 4th puncture. In all of the 9 patients, at least one of the four punctures yielded an adequate specimen for histopathological diagnosis, and malignancy was confirmed in 3 patients. In two of these 3 patients, the $5^{\text {th }}$ or subsequent punctures, which were out-of-protocol procedures, yielded a specimen(s) containing malignant cells, and in one patient, malignant cells were confirmed only in the cytology sample. Five patients were diagnosed as not having any malignancy as confirmed by surgical pathology and/or clinical follow-up. Follow-up data were lacking for one patient and the final diagnosis was unknown. 


\section{Histological assessment}

When the results of the 1st and 2nd punctures were analyzed, the punctures using the $22 \mathrm{G}$ needle were found to yield a

\begin{tabular}{lcc}
\hline \multicolumn{3}{c}{ Tissue sample size ${ }^{\mathrm{a}}\left[\mathrm{mm}^{2}\right]$ in glass slides } \\
\hline Total patient number $[\mathrm{N}=102]$ & Median [range] & $\mathrm{P}<0.01$ \\
22G needle & $16.4[0-108]$ & \\
25G needle & $4.9[0-20]$ & \\
\multicolumn{2}{c}{ Tissue sample size $\left[\mathrm{mm}^{2}\right]$ in virtual slides } \\
\hline Total patient number $[\mathrm{N}=65]^{\mathrm{b}}$ & Median [range] & $\mathrm{P}<0.01$ \\
22G needle & $12.2[0.6-42.6]$ & \\
25G needle & $3.1[0.2-11.7]$ & \\
\hline
\end{tabular}

Figure 5 Tissue sample size according to the needle gauge. ${ }^{\text {a }}$, size of the histology specimen $=$ minor axis $\times$ major axis; ${ }^{b}$, both the $22 \mathrm{G}$ needle as well as $25 \mathrm{G}$ needle yielded specimens containing malignant cells in the 1st and 2nd puncture. significantly larger median tissue sample size as compared to those using the $25 \mathrm{G}$ needle (median; $16.4 \mathrm{~mm}^{2}$ for the $22 \mathrm{G}$ needle vs. $4.9 \mathrm{~mm}^{2}$ for the $25 \mathrm{G}$ needle, Wilcoxon's rank-sum test; $\mathrm{P}<0.01$ ) (Table 2). Similar findings were obtained in the virtual slides of 65 patients whose slides contained malignant cells in both the specimens obtained with the $22 \mathrm{G}$ and $25 \mathrm{G}$ needles in the 1st and 2nd punctures (median; $12.2 \mathrm{~mm}^{2}$ for the $22 \mathrm{G}$ needle $v s .3 .1 \mathrm{~mm}^{2}$ for the $25 \mathrm{G}$ needle, Wilcoxon's rank-sum test; $\mathrm{P}<0.01$ ) (Figures 5,6 ).

Furthermore, in the 65 patients whose slides contained malignant cells from both the specimens obtained using the $22 \mathrm{G}$ and $25 \mathrm{G}$ needles (1st and $2 \mathrm{nd}$ punctures), the proportions of specimens that contained $\geq 30 \%$ malignant cells among the specimens obtained using the $22 \mathrm{G}$ and $25 \mathrm{G}$ needles were $78 \%$ and $80 \%$, respectively (Pearson $\chi^{2}$ test; $\left.\mathrm{P}=1.00\right)$. Furthermore, the median area occupied by $\mathrm{RBC}$ in the specimens obtained using the $22 \mathrm{G}$ needle was significantly higher than that in the specimens obtained using the $25 \mathrm{G}$ needle (Fisher's exact test; $\mathrm{P}<0.01$ ) (Table 3).

Of the 45 specimens which were diagnosed as NSCLC
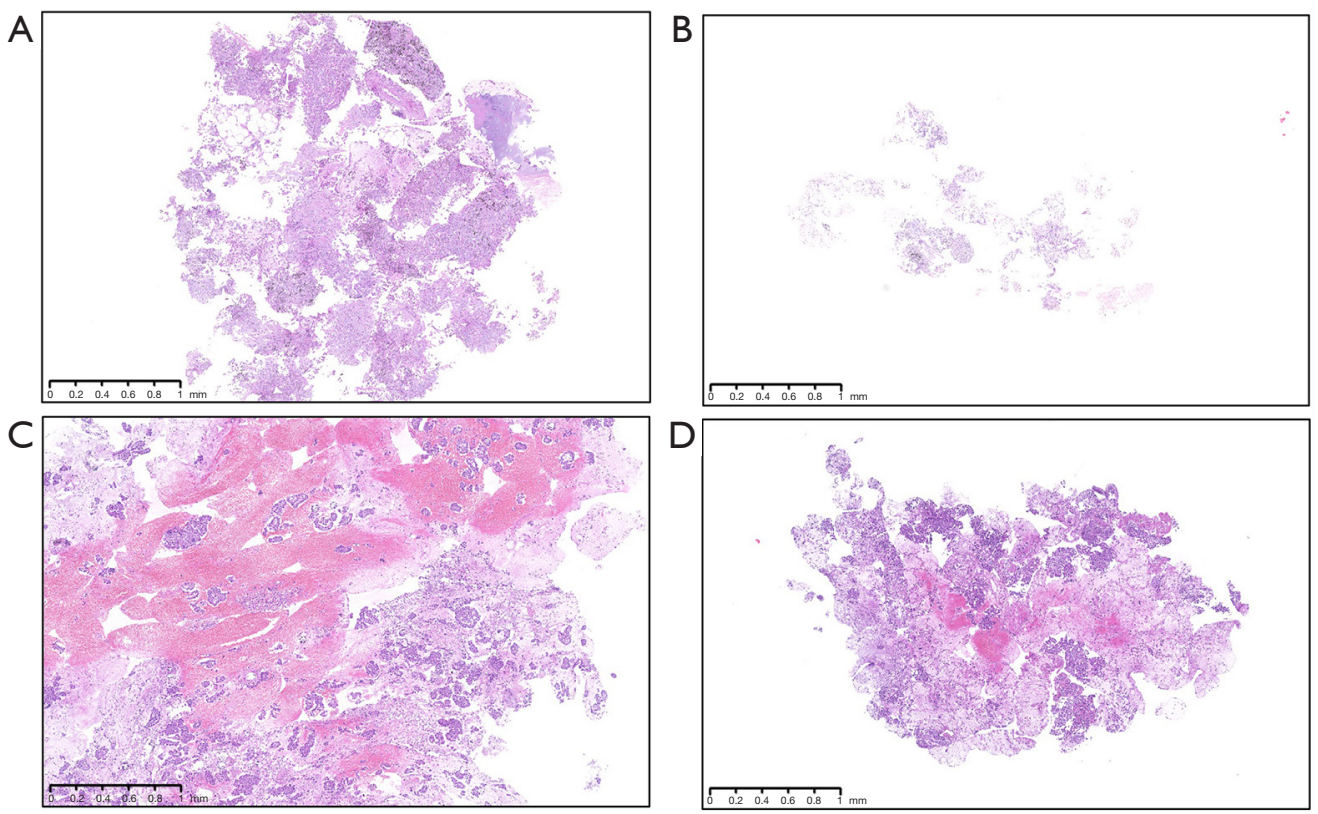

Figure 6 Representative slides showing the differences between specimens obtained using the $22 \mathrm{G}$ needle and the $25 \mathrm{G}$ needle. A and B, C, and D were obtained from the same lymph node. (A) Specimens obtained with the $22 \mathrm{G}$ needle. The specimen size was $6.3 \mathrm{~mm}^{2}$, the percentage of tumor cells was $50 \%$, and the area occupied by RBC was $0 \%$ (hematoxylin-eosin; scale bar $=1 \mathrm{~mm}$ ). (B) Specimens obtained with the $25 \mathrm{G}$ needle. The specimen size was $1.3 \mathrm{~mm}^{2}$, the percentage of tumor cells was $50 \%$, and the area occupied by RBC was $0 \%$ (hematoxylin-eosin; scale bar $=1 \mathrm{~mm}$ ). (C) Specimens obtained with the $22 \mathrm{G}$ needle. The specimen size was $17.4 \mathrm{~mm}^{2}$, the percentage of tumor cells was $70 \%$, and the area occupied by RBC was 30\% (hematoxylin-eosin; scale bar $=1 \mathrm{~mm}$ ). (D) Specimens obtained with the $25 \mathrm{G}$ needle. The specimen size was $4.9 \mathrm{~mm}^{2}$, the percentage of tumor cells was $60 \%$, and the area occupied by RBC was $2 \%$ (hematoxylin-eosin; scale bar $=1 \mathrm{~mm}$ ). 
Table 3 Percent area occupied by red blood cells in the virtual slides

\begin{tabular}{lcccc}
\hline \multirow{N}{*}{$=65^{\mathrm{a}}$} & $22 \mathrm{G}$ needle & & 25G needle & $\mathrm{P}$ \\
\cline { 2 - 3 } & $\mathrm{n}[\%]$ & $\mathrm{n}[\%]$ & $<0.01$ \\
\hline $0 \%$ & $27[42]$ & & $48[74]$ & \\
$1-10 \%$ & $17[26]$ & $14[21]$ & \\
$11-20 \%$ & $8[12]$ & $2[3]$ & \\
$21-30 \%$ & $7[11]$ & $1[2]$ & \\
$31-\%$ & $6[9]$ & 0 & \\
\hline
\end{tabular}

a, both the $22 \mathrm{G}$ needle as well as $25 \mathrm{G}$ needle yielded specimens containing malignant cells in the $1^{\text {st }}$ and $2^{\text {nd }}$ puncture.

\begin{tabular}{|c|c|c|c|}
\hline & & $22 \mathrm{G}$ needle & 25G needle \\
\hline & & n [\%] & n [\%] \\
\hline \multicolumn{4}{|l|}{ During the procedure } \\
\hline \multirow{4}{*}{$\begin{array}{l}\text { Bleeding after each } \\
\text { puncture }\end{array}$} & None & 0 & 0 \\
\hline & Mild & 101 [99] & $100[98]$ \\
\hline & Moderate & $1[1]$ & 2 [2] \\
\hline & Severe & 0 & 0 \\
\hline \multicolumn{4}{|l|}{ After the procedure } \\
\hline Bloody sputum & Grade 1 & \multicolumn{2}{|c|}{$13[13]$} \\
\hline Wheezing & Grade 2 & \multicolumn{2}{|c|}{$1[1]$} \\
\hline Nausea & Grade 1 & \multicolumn{2}{|c|}{$1[1]$} \\
\hline
\end{tabular}

Figure 7 Adverse events during and after the procedure

in both the specimens obtained using the $22 \mathrm{G}$ and $25 \mathrm{G}$ needles (1st and 2 nd punctures), the median number of malignant cells was significantly higher in the specimens obtained using the $22 \mathrm{G}$ needle than in the specimens obtained using the $25 \mathrm{G}$ needle, [median (range); 626 $(5-4,200)$ for the $22 \mathrm{G}$ needle $v$ s. $400(5-1,652)$ for the $25 \mathrm{G}$ needle, Wilcoxon's rank-sum test; $\mathrm{P}<0.01)$.

\section{Safety analysis}

Moderate or severe bleeding events due to TBNA were observed in one patient when the $22 \mathrm{G}$ needle was being used and in 2 patients when the $25 \mathrm{G}$ needle was being used (Figure 7). After the procedure, the most frequent $\mathrm{AE}$ reported was grade 1 bloody sputum (13 events; $13 \%$ ), followed by one (1\%) event of grade 2 wheezing (asthma attack), and 1 (1\%) grade 1 event of nausea. None of the subjects developed pulmonary infection, mediastinitis or pneumothorax.

\section{Discussion}

This study is, to the best of our knowledge, the first prospective randomized trial to compare the rate of yield of histology specimens containing malignant cells and rate of yield of adequate specimens for histopathological diagnosis between EBUS-TBNA performed using a 22G needle and $25 \mathrm{G}$ needle for the diagnosis of hilar/mediastinal lymph node metastasis in patients with suspected or definitive diagnosis of lung cancer. We also describe the sample quantity and quality, including the tissue sample size, the percentage of specimens showing malignant cells, the number of malignant cells contained in each specimen, and the percent area of the specimen occupied by RBC.

We found the yield rate of histology specimens containing malignant cells and the yield rate of adequate specimens for histopathological diagnosis were comparable between TBNA performed using a $25 \mathrm{G}$ needle and that using a $22 \mathrm{G}$ needle. These results were consistent with those reported from a previous study that conducted a retrospective comparison of the usefulness of a $22 \mathrm{G}$ needle and $25 \mathrm{G}$ needle for EBUS-TBNA, although they did not puncture the same lymph nodes with the two needles (7). In that study, the diagnostic sensitivities of EBUS-TBNA using the $22 \mathrm{G}$ and $25 \mathrm{G}$ needles were $89 \%$ and $78 \%$, respectively. Adequate samples for histopathologic diagnosis were obtained in $92 \%$ of cases of EBUS-TBNA using a $22 \mathrm{G}$ needle and $92 \%$ of cases of EBUS-TBNA using a $25 \mathrm{G}$ needle. There was no statistically significant difference in the diagnostic sensitivity or the sample adequacy rate between EBUS-TBNA performed using the two gauges of needles in that study. Furthermore, a small retrospective study which compared $22 \mathrm{G}$ and $25 \mathrm{G}$ needles among 10 patients who underwent EBUS-TBNA using both $22 \mathrm{G}$ and $25 \mathrm{G}$ needles (8). In that study, the diagnostic yields of EBUS-TBNA using the $22 \mathrm{G}$ needle was $80 \%$ and $25 \mathrm{G}$ needle was $60 \%$, respectively. The diagnostic yields of $22 \mathrm{G}$ and $25 \mathrm{G}$ needle were also thought to be comparable in that study.

On the other hand, several studies have demonstrated that EUS-FNA using a $25 \mathrm{G}$ needle shows a higher diagnostic sensitivity for pancreatic malignancy than that using a $22 \mathrm{G}$ needle (13-15). The reason for the observed superior diagnostic accuracy of the $25 \mathrm{G}$ needle in the aforementioned EUS-FNA studies could be attributable to 
the use of $25 \mathrm{G}$ needle being associated with fewer bloody aspirations, needle passage into lesions that are technically easier to access with the $25 \mathrm{G}$ needle, because of the greater flexibility (16). In our EBUS-TBNA study, although the percent area of the specimen occupied by $\mathrm{RBC}$ was higher in the case of EBUS-TBNA performed with a $22 \mathrm{G}$ needle as compared to that performed with a $25 \mathrm{G}$ needle, as in the EUS-FNA studies mentioned above, the tissue sample size and total number of malignant cells were also larger in the case of EBUS-TBNA performed with a $22 \mathrm{G}$ needle. As a result, the presence of blood may not obscure the diagnostic yield of EBUS-TBNA performed with a $22 \mathrm{G}$ needle. Moreover, we enrolled patients with hilar/mediastinal lymphadenopathy which were obviously suspected as being metastases from the primary lung cancer. Consequently, there were no patients in whom the lesion could be punctured only with a $25 \mathrm{G}$ needle and not with a $22 \mathrm{G}$ needle. These results imply that a few lesions which were technically difficult to access and required the increased flexibility of the $25 \mathrm{G}$ needle might have been included in our study, and may explain the difference in the results between the EBUS-TBNA and EUS-FNA studies conducted to compare the usefulness of $22 \mathrm{G}$ and $25 \mathrm{G}$ needles.

Meanwhile, the yield rate of histology specimens containing malignant cells obtained with the $22 \mathrm{G}$ needle was significantly higher when the EBUS-TBNA was performed by expert operators as compared to trainee operators, while no such difference was observed for the procedure performed using the $25 \mathrm{G}$ needle. Several studies have shown an association between the diagnostic accuracy and operator experience $(17,18)$, in that in the procedures performed using the $22 \mathrm{G}$ needle, the diagnostic accuracy showed a trend towards improvement with increasing operator experience. Thus, the association between the diagnostic accuracy and operator experience in our study was concordant with the finding of previous studies for the procedures performed using the $22 \mathrm{G}$ needle. On the other hand, this study is the first study to investigate those associations using the $25 \mathrm{G}$ needle. The characteristic result obtained with the use of the $25 \mathrm{G}$ needle, that there was no difference in the diagnostic accuracy between expert operators and trainee operators, may imply that the use of the $25 \mathrm{G}$ needle may be easier for trainee operators because of improved handleability and increased flexibility of the $25 \mathrm{G}$ needle, as in EUS-FNA (16). Therefore, the 25G needle may be a good option for trainee operators. On the other hands, 22G needles had been usually used in clinical practice until $25 \mathrm{G}$ needle became available. Therefore, expert operators had a little experience of using $25 \mathrm{G}$ needle, and it was possible that expert operators were not familiar with use of $25 \mathrm{G}$ needle as well as trainee operators. This was another possible cause that there was no difference of diagnostic accuracy between expert operators and trainee operators when using $25 \mathrm{G}$ needle.

As compared to the tissue sample size obtained with the $25 \mathrm{G}$ needle, the procedure performed with the $22 \mathrm{G}$ needle yielded larger samples without any decrease in the percentage of malignant cells. Furthermore, the number of malignant cells was also higher in the samples obtained with the $22 \mathrm{G}$ needle than in those obtained with the $25 \mathrm{G}$ needle. There are no reports of previous studies conducted to compare the sizes of the tissue samples obtained by the needle gauge used. A retrospective trial which compared the $21 \mathrm{G}$ needle and $22 \mathrm{G}$ needle found that the $21 \mathrm{G}$ needle provided better histological specimens with an increased number of malignant cells (19). Although the sizes of the needles used differed between our study and the previous study, the results that a larger number of malignant cells can be obtained using a larger needle were consistent. In advanced NSCLC, biomarker analysis by NGS using tissue samples is considered as a standard of care and necessary for tailoring the best chemotherapy to the cancer characteristics of individual patients (20). Prior studies have demonstrated the feasibility of NGS in TBNA samples of lung adenocarcinoma (21-24). These studies have shown that the presence of a larger number of malignant cells was associated with higher success rates of NGS. Furthermore, in a study that evaluated the sample size, number of malignant cells in biopsy samples of lung cancer and the success rate of NGS, larger sample sizes and higher numbers of malignant cells in the samples were associated with higher success rates of NGS (25). Thus, our finding that TBNA using the $22 \mathrm{G}$ needle yielded larger sizes of tissue samples without a decrease in the percentage of malignant cells and samples containing a higher proportion of malignant cells may indicate that TBNA performed with the $22 \mathrm{G}$ needle may also be associated with an improved success rate of biomarker analysis in patients with advanced NSCLC.

The $25 \mathrm{G}$ needle may be considered as allowing improved handling, providing increased flexibility, facilitating access to the lymph node in locations that are technically difficult to reach, and being less traumatic (26). Nevertheless, in our study, the procedure times were similar between EBUSTBNA using the $22 \mathrm{G}$ needle and the $25 \mathrm{G}$ needle. This could be because the number of patients with involvement 
of lymph nodes that were technically difficult to access and required the increased flexibility of the $25 \mathrm{G}$ needle, such as station \#2L or $4 \mathrm{~L}$ lymph nodes, was small in our study. Moreover, the similar degrees of bleeding observed after biopsy between the $22 \mathrm{G}$ needle and $25 \mathrm{G}$ needle suggested that the $25 \mathrm{G}$ needle may not actually be significantly less traumatic or less invasive after all.

There were several limitations to this study. First of all, in our study, we included patients with hilar/mediastinal lymphadenopathy, which were obviously suspected as representing lymph node metastasis from primary lung cancer, but not patients who needed mediastinal staging. EBUS-TBNA for mediastinal staging is conducted for determining the best curative treatment strategy such as surgical resection or chemoradiotherapy. So that the main purpose is different from EBUS-TBNA for patients who were highly suspected of having lymph node metastasis from lung cancer, of which purpose is making a definitive diagnosis of lung cancer and making a biomarker analysis. This is why we exclude patients who needed mediastinal staging. Therefore, we did not compare the efficiency for mediastinal staging in lung cancer between the $22 \mathrm{G}$ needle and $25 \mathrm{G}$ needle and further investigation is needed.

Furthermore, as the same reason of our patient inclusion criteria, the diagnostic accuracy for benign diseases, such as sarcoidosis and tuberculous lymphadenitis, between the $22 \mathrm{G}$ needle and $25 \mathrm{G}$ needle are unclear. Therefore, we think further prospective evaluation in a population subset which included benign diseases such as sarcoidosis will be needed. Second, only a few lymph nodes which considered to be difficult to access were included in this study. Third, although our pathologists were blinded to the gauge of the needle used to obtain the samples, the operators were not blinded. This may have led to subconscious bias, although the operators performed the EBUS-TBNA procedure with the best intentions in the same manner. Fourth, it was considered that large sample size and high number of malignant cells are associated with the high success rate of NGS (25), in that point, we thought $22 \mathrm{G}$ needle was more suitable for NGS than $25 \mathrm{G}$ needle. But we did not directly compare the success rate of molecular test including NGS between the $22 \mathrm{G}$ and $25 \mathrm{G}$ needle. Therefore, to evaluate the optimal needle size for the analysis of biomarker including NGS, we think further prospective study will be needed.

\section{Conclusions}

The present results indicate that use of a $22 \mathrm{G}$ needle and
25G needle for EBUS-TBNA provided similar diagnostic yields for lymph node metastasis in patients with lung cancer. As compared to the $25 \mathrm{G}$ needle, the $22 \mathrm{G}$ needle was slightly more advantageous, in that it could obtained larger tumor tissue samples and specimens containing higher numbers of malignant cells that potentially better samples for NGS and molecular analysis. Therefore, while we prefer to use the $22 \mathrm{G}$ needle, a $25 \mathrm{G}$ needle is also a useful option for EBUS-TBNA for the diagnosis of lymph node metastasis in patients with lung cancer.

\section{Acknowledgments}

We would like to thank Takashi Ikeno, Clinical Research Support Office, National Cancer Center Hospital East, Kashiwa, Japan for providing statistical analysis support. Disclaimer: This study has been presented in part at the World Conference on Lung Cancer 2020.

Funding: This work was supported by the Japan Agency for Medical Research and Development (grant number JP21ck0106289, JP21ck0106294, JP20ck0106411, JP20ck0106450).

\section{Footnote}

Reporting Checklist: The authors have completed the CONSORT reporting checklist. Available at https://dx.doi. org/10.21037/tlcr-21-480

Trial Protocol: Available at https://dx.doi.org/10.21037/tlcr21-480

Data Sharing Statement: Available at https://dx.doi. org/10.21037/tlcr-21-480

Peer Review File: Available at https://dx.doi.org/10.21037/ tlcr-21-480

Conflicts of Interest: All authors have completed the ICMJE uniform disclosure form (available at https://dx.doi. org/10.21037/tlcr-21-480). Dr. Sakai reports personal fees from AstraZeneca., outside the submitted work; Dr. Udagawa reports grants from Abbvie, MSD, AMGEN, Daiichi Sankyo and personal fees from Abbvie, MSD, Boehringer Ingelheim, Chugai, Taiho, Ono, Bristol-Myers Squibb, Amco, Daiichi Sankyo, AstraZeneca, outside the submitted work; Dr. Kirita reports personal fees from Olympus, Boston Scientific, MSD, Pfizer, Boeriger 
Ingelheim, Novartis, Chugai, Ono, Amco, Thermo Fisher Scientific, AstraZeneca, Lilly, outside the submitted work; Dr. Ota reports personal fees from AstraZeneca, Chugai, Boehringer Ingelheim, Cook Medical, MSD, Ono, Taiho, outside the submitted work; Dr. Zenke reports grants from AstraZeneca, MSD, Merck Serono and personal fees from AstraZeneca, MSD, Merck Serono, Lilly, Chugai, Ono, Taiho, Boheringer Ingelheim, Bristol-Myers Squibb, outside the submitted work; Dr. Matsumoto reports grants from Lilly, MSD, Novartis, Daiichi Sankyo, Chugai, Merck and personal fees from Novartis, Chugai, AstraZeneca, Guardant Health, Thermo Fisher Scientific, outside the submitted work; Dr. Yoh reports grants from AstraZeneca, Lilly, Pfizer, Taiho, Bayer, Takeda, Daiichi Sankyo, MSD, Abbvie and personal fees from AstraZeneca, Bristol-Myers Squibb, Chugai, Lilly, Taiho, Novartis, Daiichi Sankyo, Kyowa Kirin, Janssen, Boehringer Ingelheim, outside the submitted work; Dr. Niho reports grants from Lilly, AstraZeneca, MSD, Pfizer, Chugai, Merck Serono, Ono, Teijin, Sanofi, Shionogi, Boehringer Ingelheim, Taiho, Takeda and personal Lilly, AstraZeneca, MSD, Pfizer, Chugai, Ono, Boehringer Ingelheim, Taiho, Kyorin, Janssen, Novartis, outside the submitted work; Dr. Ishii reports grants from Ono, Daiichi Sankyo, Novartis, ORGANOGENIX and personal fees from Ono, Daiichi Sankyo, Novartis, Lilly, Taiho, Roche Diagnostics, Chugai, Oncolys BioPharma, outside the submitted work; Dr. Goto reports grants from MSD, Merck, Lilly, Amgen Astellas BioPharma, Chugai, Eisai, Ono, NEC, Janssen Pharmaceutical, Amgen, Daiichi Sankyo, Taiho, Kyowa Kirin, MEDICAL \& BIOLOGICAL LABORATORIES, Boehringer Ingelheim, Takeda, Sumitomo Dainippon Pharm, Xcoo, Sysmex, Pfizer, KISSEI, Bristol-Myers Squibb, Merck Serono, AstraZeneca, Astellas, Loxo Oncology, Merus, Spectrum Pharmaceuticals, Ignyta, Shanghai Haihe Pharmaceutical, Thermo Fisher Scientific and personal fees from MSD, Lilly, Amgen Astellas BioPharma, Chugai, Eisai, Ono, Janssen Pharmaceutical, Amgen, Takeda, Thermo Fisher Scientific, Novartis, Nippon Kayaku, Otsuka, Guardant Health, outside the submitted work. The other authors have no conflicts of interest to declare.

Ethical Statement: The authors are accountable for all aspects of the work in ensuring that questions related to the accuracy or integrity of any part of the work are appropriately investigated and resolved. The study was conducted in accordance with the Declaration of Helsinki (as revised in 2013). The study was approved by the Institutional Review Board of the study center (National Cancer Center Japan: approval number 2018-016), and written informed consent was obtained from all participants.

Open Access Statement: This is an Open Access article distributed in accordance with the Creative Commons Attribution-NonCommercial-NoDerivs 4.0 International License (CC BY-NC-ND 4.0), which permits the noncommercial replication and distribution of the article with the strict proviso that no changes or edits are made and the original work is properly cited (including links to both the formal publication through the relevant DOI and the license). See: https://creativecommons.org/licenses/by-nc-nd/4.0/.

\section{References}

1. Silvestri GA, Gonzalez AV, Jantz MA, et al. Methods for staging non-small cell lung cancer: Diagnosis and management of lung cancer, 3 rd ed: American College of Chest Physicians evidence-based clinical practice guidelines. Chest 2013;143:e211S-50S.

2. Yasufuku K, Nakajima T, Waddell T, et al. Endobronchial ultrasound-guided transbronchial needle aspiration for differentiating N0 versus N1 lung cancer. Ann Thorac Surg 2013;96:1756-60.

3. Kim L, Tsao MS. Tumour tissue sampling for lung cancer management in the era of personalised therapy: what is good enough for molecular testing? Eur Respir J 2014;44:1011-22.

4. Korpanty GJ, Graham DM, Vincent MD, et al. Biomarkers That Currently Affect Clinical Practice in Lung Cancer: EGFR, ALK, MET, ROS-1, and KRAS. Front Oncol 2014;4:204.

5. Aguiar PN Jr, De Mello RA, Hall P, et al. PD-L1 expression as a predictive biomarker in advanced non-small-cell lung cancer: updated survival data. Immunotherapy 2017;9:499-506.

6. Wahidi MM, Herth F, Yasufuku K, et al. Technical Aspects of Endobronchial Ultrasound-Guided Transbronchial Needle Aspiration: CHEST Guideline and Expert Panel Report. Chest 2016;149:816-35.

7. Di Felice C, Young B, Matta M. Comparison of specimen adequacy and diagnostic accuracy of a 25 -gauge and 22-gauge needle in endobronchial ultrasoundguided transbronchial needle aspiration. J Thorac Dis 2019;11:3643-9.

8. Sakaguchi T, Inoue T, Miyazawa T, et al. Comparison 
of the 22-gauge and 25-gauge needles for endobronchial ultrasound-guided transbronchial needle aspiration. Respir Investig 2021;59:235-9.

9. Yasufuku K, Chiyo M, Koh E, et al. Endobronchial ultrasound guided transbronchial needle aspiration for staging of lung cancer. Lung Cancer 2005;50:347-54.

10. Izumo T, Sasada S, Watanabe J, et al. Comparison of two $22 \mathrm{G}$ aspiration needles for histologic sampling during endobronchial ultrasound-guided transbronchial needle aspiration (EBUS-TBNA). Jpn J Clin Oncol 2014;44:841-5.

11. Travis WD, International Agency for Research on C. WHO classification of tumours of the lung, pleura, thymus and heart. 4th ed. World Health Organization classification of tumours. International Agency for Research on Cancer; 2015.

12. Hetzel J, Eberhardt R, Herth FJ, et al. Cryobiopsy increases the diagnostic yield of endobronchial biopsy: a multicentre trial. Eur Respir J 2012;39:685-90.

13. Imazu H, Uchiyama $Y$, Kakutani $H$, et al. A prospective comparison of EUS-guided FNA using 25-gauge and 22-gauge needles. Gastroenterol Res Pract 2009;2009:546390.

14. Yusuf TE, Ho S, Pavey DA, et al. Retrospective analysis of the utility of endoscopic ultrasound-guided fineneedle aspiration (EUS-FNA) in pancreatic masses, using a 22-gauge or 25-gauge needle system: a multicenter experience. Endoscopy 2009;41:445-8.

15. Madhoun MF, Wani SB, Rastogi A, et al. The diagnostic accuracy of 22-gauge and 25-gauge needles in endoscopic ultrasound-guided fine needle aspiration of solid pancreatic lesions: a meta-analysis. Endoscopy 2013;45:86-92.

16. Sakamoto H, Kitano M, Komaki T, et al. Prospective comparative study of the EUS guided 25-gauge FNA needle with the 19-gauge Trucut needle and 22-gauge FNA needle in patients with solid pancreatic masses. J Gastroenterol Hepatol 2009;24:384-90.

17. Steinfort DP, Hew MJ, Irving LB. Bronchoscopic evaluation of the mediastinum using endobronchial ultrasound: a description of the first 216 cases carried out at an Australian tertiary hospital. Intern Med J 2011;41:815-24.

18. Groth SS, Whitson BA, D'Cunha J, et al. Endobronchial ultrasound-guided fine-needle aspiration of mediastinal lymph nodes: a single institution's early learning curve. Ann Thorac Surg 2008;86:1104-9; discussion 1109-10.

19. Nakajima T, Yasufuku K, Takahashi R, et al. Comparison of 21-gauge and 22-gauge aspiration needle during endobronchial ultrasound-guided transbronchial needle aspiration. Respirology 2011;16:90-4.

20. Lim SM, Kim EY, Kim HR, et al. Genomic profiling of lung adenocarcinoma patients reveals therapeutic targets and confers clinical benefit when standard molecular testing is negative. Oncotarget 2016;7:24172-8.

21. Gleeson FC, Kipp BR, Levy MJ, et al. Lung cancer adrenal gland metastasis: Optimal fine-needle aspirate and touch preparation smear cellularity characteristics for successful theranostic next-generation sequencing. Cancer Cytopathol 2014;122:822-32.

22. Zhang Y, Li J, Hua P, et al. Targeted next-generation sequencing in cytology specimens for molecular profiling of lung adenocarcinoma. Int J Clin Exp Pathol 2018;11:3647-55.

23. Scarpa A, Sikora K, Fassan M, et al. Molecular typing of lung adenocarcinoma on cytological samples using a multigene next generation sequencing panel. PLoS One 2013;8:e80478.

24. Velizheva NP, Rechsteiner MP, Wong CE, et al. Cytology smears as excellent starting material for nextgeneration sequencing-based molecular testing of patients with adenocarcinoma of the lung. Cancer Cytopathol 2017;125:30-40.

25. Nemoto D, Yokose T, Katayama K, et al. Tissue surface area and tumor cell count affect the success rate of the Oncomine Dx Target Test in the analysis of biopsy tissue samples. Thorac Cancer 2021;12:194-200.

26. Stoy SP, Segal JP, Mueller J, et al. Feasibility of Endobronchial Ultrasound-guided Transbronchial Needle Aspiration Cytology Specimens for Next Generation Sequencing in Non-small-cell Lung Cancer. Clin Lung Cancer 2018;19:230-8.e2.

Cite this article as: Sakai T, Udagawa H, Kirita K, Nomura S, Itotani R, Tamiya Y, Sugimoto A, Ota T, Naito T, Izumi H, Nosaki K, Ikeda T, Zenke Y, Matsumoto S, Yoh K, Niho S, Nakai T, Ishii G, Goto K. Comparison of the efficiency of endobronchial ultrasound-guided transbronchial needle aspiration using a $22 \mathrm{G}$ needle versus $25 \mathrm{G}$ needle for the diagnosis of lymph node metastasis in patients with lung cancer: a prospective randomized, crossover study. Transl Lung Cancer Res 2021;10(9):3745-3758. doi: 10.21037/tlcr-21-480 